Document downloaded from:

http://hdl.handle.net/10251/81805

This paper must be cited as:

Torregrosa Jaime, B.; Payá Herrero, J.; Corberán Salvador, JM. (2016). Application of magnetic cooling in electric vehicles. Science and Technology for the Built Environment. 22(5):544-555. doi:10.1080/23744731.2016.1186459.

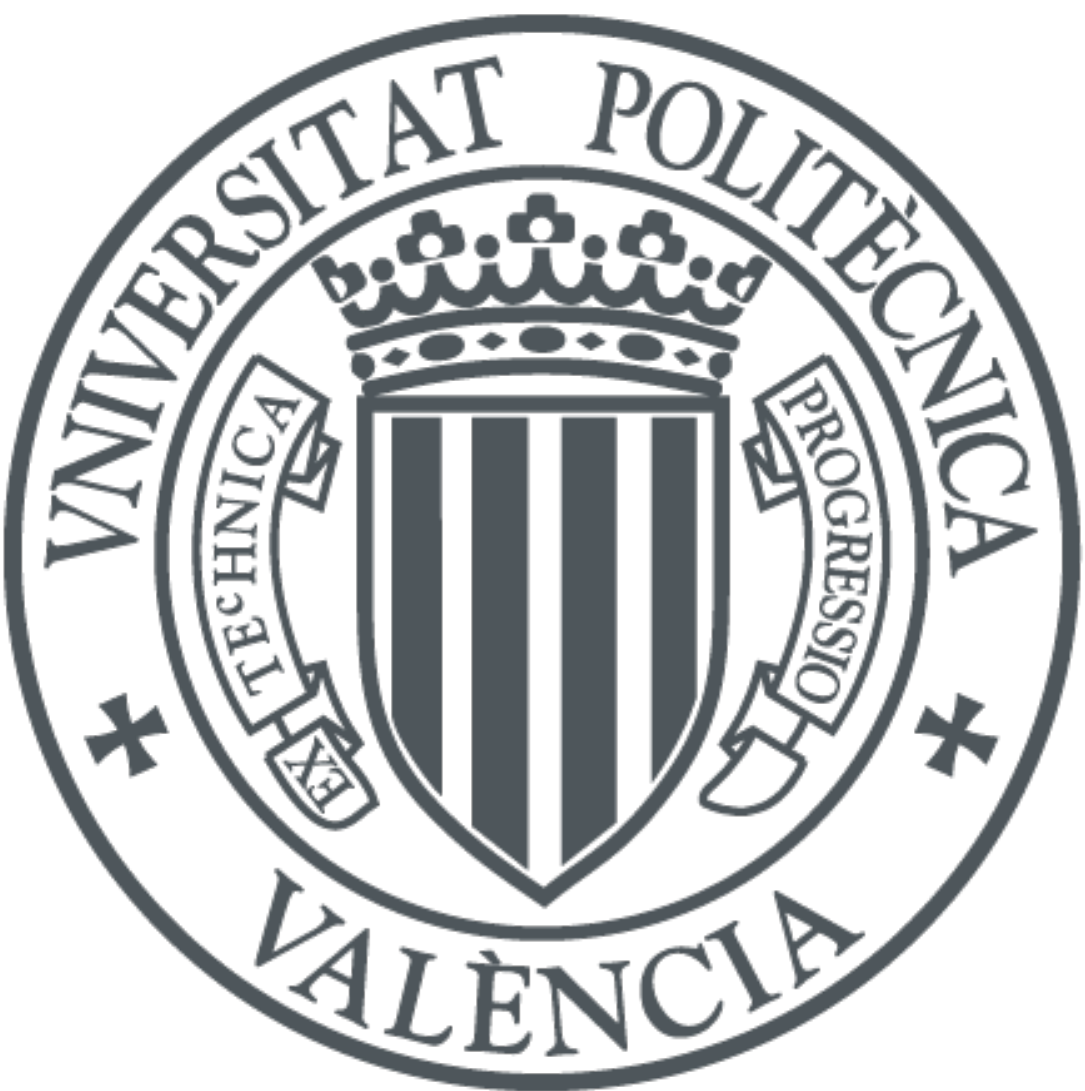

The final publication is available at

Copyright Taylor \& Francis

Additional Information 


\section{Application of magnetic cooling in electric vehicles}

The features of an active magnetic regenerator refrigerator (AMRR) are determined for its application in mobile air-conditioning (MAC) systems. The thermal requirements of an electric vehicle have been firstly obtained and result in a cooling demand of $3.03 \mathrm{~kW}$ at a temperature span of $29.3 \mathrm{~K}$. A comprehensive parametric study has been conducted in order to find the AMRR design and working parameters that fulfill the vehicle needs with a minimum electric consumption and device mass. Specifically, a permanent-magnet parallel-plate AMRR made of Gd-like materials is considered. According to the possibilities of current prototypes, in the study the cycle frequencies have been limited to $10 \mathrm{~Hz}$ and the applied magnetic fields, to 1.4 T. The results show that an AMRR made of plates between 30 and $40 \mu \mathrm{m}$ thick and channels between 20 and $40 \mu \mathrm{m}$ high could meet the vehicle demand with a COP between 2 and 4 and a total mass between 20 and $50 \mathrm{~kg}$. Compared to vapor-compression devices for MAC systems (COP=2.5 and mass 12 to $15 \mathrm{~kg}$ ), the AMRR works optimally with fluid flow rates at least 3 times larger. In order to integrate AMRRs into MAC systems, the hydraulic loops should be consequently redesigned.

\section{Introduction}

Magnetic refrigeration is a cooling technology based on the magnetocaloric effect. Its application at room temperature has been intensively studied during the last decades as an alternative to the vaporcompression systems. Unlike the latter, magnetic refrigerators do not depend on greenhouse gases but on a solid refrigerant and typically an aqueous working fluid. Other main advantages of this cooling technology are its lower maintenance (less leaks, Jacobs et al., (2014)) and its theoretically higher efficiency. These features make magnetic refrigeration a potentially attractive option for mobile air-conditioning (MAC) systems, whose performance is key to reduce the energy consumption of vehicles. In average weather conditions, the use of the air conditioning (AC) can reduce the fuel economy of mid-sized petrol-driven automobiles by $20 \%$ (Farrington and Rugh, 2000) and the driving range of electric vehicles by 33\% (Lee et al., 2013).

Mobile air-conditioning is a challenging application for magnetic refrigeration at room temperature. In vehicles, installed cooling capacity ranges between 3 and $5 \mathrm{~kW}$ while typical working temperatures are 5 to 
$10{ }^{\circ} \mathrm{C}$ in the cold side and 45 to $55^{\circ} \mathrm{C}$ in the hot side. No published prototype has reached such performance up to date (Kitanovski et al., 2015). In order to determine the feasibility of magnetic refrigerators in MAC systems, its performance beyond the state-of-the-art must be analysed by means of simulation.

In this paper, a parametric study is conducted with the purpose of determining the range of design and operating parameters of a permanent-magnet parallel-plate active magnetic regenerator refrigerator (AMRR) that optimally fulfills the cooling requirements of a vehicle. The discussion focuses in minimizing simultaneously the electric consumption and the mass of the device. In MAC systems, a minimal mass of the components is a relevant design target, given that any additional load increases the energy consumption of the vehicle.

Comprehensive parametric studies have already been performed with the purpose of finding the design and operating parameters that optimize the parallel-plate active magnetic regenerator (AMR) performance. Nielsen et al. (2010) analysed the effect of the channel and plate thicknesses between 0.2 and $1 \mathrm{~mm}$ combined with cycle frequencies (f) from 0.14 to $4 \mathrm{~Hz}$ and thermal utilizations (U) between 0.14 and 6.4, for a range of temperature spans. Among other trends, they found that the $\mathrm{U}$ should range between 0.2 and 1 . Tušek et al. (2013) studied in detail the optimal geometry of the AMR from the thermohydraulic point of view. They considered a fixed temperature span of $15 \mathrm{~K}$, two values of the frequency $(0.5$ and $3 \mathrm{~Hz})$ and the corresponding optimal fluid flow rate. The analysis included plates from 0.1 to $1 \mathrm{~mm}$ thick, channels from 0.01 to $0.1 \mathrm{~mm}$ high and regenerators from 40 to $200 \mathrm{~mm}$ long. Under these conditions, they found that a channel height of $0.035 \mathrm{~mm}$ maximized the specific cooling capacity and $0.075 \mathrm{~mm}$ maximized the COP regardless of the other parameters. However, both of these studies were based in material properties modelled with the mean field theory and did not consider the demagnetizing effect, which leads to an overestimation of the AMR performance (Nielsen et al., 2011).

The optimization of the AMRR mass and performance, including both the magnet and the AMR, has also been addressed by a number of researchers. These studies focus in the overall cost of the device as the target variable. The parameters varied include the applied magnetic field, some of the regenerator dimensions, the operating parameters (f and $\mathrm{U}$ ) and sometimes the thermal requirements. Bjørk et al. (2011) determined the minimum building cost of an AMRR based on its total mass. Tura and Rowe (2014) minimized the total cost of a packed-spheres AMRR, that is the sum of its building and operating costs, with the purpose of 
identifying target refrigerant properties. To do so, they employed an analytical AMR model and considered an ideally graded regenerator bed. Recently, Bjørk et al. (2015) performed a similar lifetime analysis focused on a realistic practical application for current small AMRRs, namely a domestic refrigerator. Unlike the former studies, they employed experimental Gd properties and swept all the parameters related to the dimensions of a packed-sphere AMRR. They considered cycle frequencies up to $10 \mathrm{~Hz}$, achievable by current prototypes. In agreement with Tura and Rowe (2014), they found an optimal magnetic field around $1.4 \mathrm{~T}$.

As the latter study, the present work considers the possibilities of current AMRR prototypes and MCM materials, including the demagnetizing effect. However a much more demanding application is targeted. Another main novelty is the analysed parameter space, which includes 5 different design parameters of parallel-plate AMRRs (instead of packed-spheres) and the 2 operating parameters. Moreover, the range of AMR dimensions explored goes beyond the published studies to the knowledge of the authors. Finally, a signficant difference with respect to the previous analyses is that the electric consumption and the mass of the device are not merged into only one target variable. The solution shown is therefore a line of optimal pairs efficiency-mass.

The sizing of an AMR device for an electric vehicle was previously addressed by the authors in the frame of the FP7 European Project ICE (Torregrosa-Jaime et al., 2014b). The former publication detailed the approach followed to calculate the thermal requirements of the vehicle and showed the simulation results of an AMR with a proposed design. In this new work, the requirements have been updated and the whole AMRR is considered and optimized for cooling.

\section{Mobile air-conditioning requirements}

The air-conditioning system of a vehicle provides cooling power to the cabin while rejecting heat to the outside. An AMRR can perform this task if it is integrated into a hydraulic loop that carries the working fluid to each side. This layout is specially convenient in electric vehicles for the future integration of the thermal systems (Leighton, 2015). The mobile air-conditioning system developed during the European Project ICE for a commercial electric minibus (Torregrosa-Jaime et al., 2013b) presents this architecture (Figure 1), therefore it is an appropriate base to calculate the requirements of an AMRR for vehicle applications. The 
design targets considered in this study include meeting the cooling demand at a given working temperatures, minimizing mass and maximizing system efficiency.

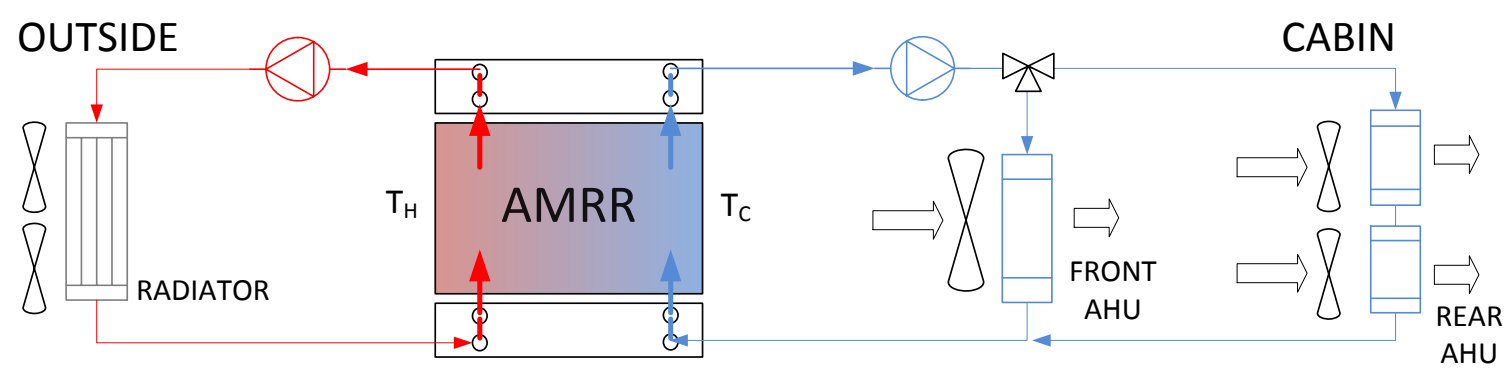

Figure 1. Target mobile air-conditioning system.

The target mobile air-conditioning system (Figure 1) consists of an AMRR and the hydraulic loops containing the water-to-air heat exchangers, namely the vehicle's radiator in the ambient side and several airhandling units (AHU) in the cabin side. The task of this system is to keep the cabin air at the comfort target conditions. The specific characteristics of the conventional system components have been detailed in previous publications (Torregrosa-Jaime et al., 2013b, Torregrosa-Jaime et al., 2014a, Torregrosa-Jaime et al., 2015).

A global vehicle model comprising the presented system and the vehicle cabin (Bjurling et al., 2014; Torregrosa-Jaime et al., 2014a) has been employed to determine the thermal requirements of the minibus under the design summer conditions fixed within the ICE Project consortium (Table 1). The required cooling capacity is calculated to overcome the diverse heat gains in the cabin as well as heat gains from the electric auxiliaries and the hydraulic system. The working temperatures in the loops, namely the inlet temperatures to the AMRR in the hot side $\left(T_{H}\right)$ and in the cold side $\left(T_{C}\right)$, have been obtained with the heat balance equation in place of the refrigerator, $\dot{\mathrm{Q}}_{\mathrm{h}}=\dot{\mathrm{Q}}_{\mathrm{c}}+\dot{\mathrm{W}}$ and $\mathrm{COP}=\dot{\mathrm{Q}}_{\mathrm{c}} / \mathrm{W}$, taking into account the characteristics of the heat exchangers ( Torregrosa-Jaime et al., 2015). A sensitivity analysis revealed that the COP value has a minor influence in the values of the working temperatures in the studied setup, so a typical $\mathrm{COP}=2.5$ has been considered. 


\begin{tabular}{|c|c|}
\hline Table 1. MAC design conditions and thermal requirements \\
\hline Design conditions & Values \\
\hline Comfort target & $25^{\circ} \mathrm{C} @ 50 \% \mathrm{RH}$ \\
\hline External conditions & $35^{\circ} \mathrm{C} @ 60 \% \mathrm{RH}$ \\
\hline Occupants & $8($ driver +7 passengers $)$ \\
\hline Air flow rate - front AHU & $311 \mathrm{~m}^{3} \mathrm{~h}^{-1}$ \\
\hline Air flow rate - rear AHU & $500 \mathrm{~m}^{3} \mathrm{~h}^{-1}$ \\
\hline Air flow rate - radiator & $2187 \mathrm{~m}^{3} \mathrm{~h}^{-1}$ \\
\hline Thermal requirements & \\
\hline Cooling capacity $[\mathrm{W}]$ & 3027 \\
\hline $\left.\mathrm{TC}_{\mathrm{C}}{ }^{\circ} \mathrm{C}\right]$ & 12.78 \\
\hline $\mathrm{TH}_{\mathrm{H}}\left[{ }^{\circ} \mathrm{C}\right]$ & 42.13 \\
\hline Temperature span $[\mathrm{K}]$ & 29.4 \\
\hline
\end{tabular}

As mentioned above, the mass of the auxiliary systems in a vehicle must be minimal given that any additional load implies increasing fuel or electric consumption by the powertrain. Moreover the cost of AMR devices is directly related to its mass (Bjørk et al., 2011), so it is definitely a parameter to be minimised in this particular application. Automotive vapour-compression devices weight from 12 to $15 \mathrm{~kg}$ approximately.

The AC system efficiency depends on the electricity consumption necessary to produce the useful effect, that is the cooling power delivered to the cabin. The electric consumption associated to the heat pump is the sum of the power demanded by the device itself and the one due to the coolant pumping. Under the conditions specified in Table 1, the state-of-art vapour-compression device considered as baseline in the ICE Project (Torregrosa-Jaime et al., 2013a) consumes $1230 \mathrm{~W}$ to meet the cooling demand.

The pumping power depends on the working fluid flow rate, which in conventional systems is usually selected to achieve a compromise between heat transfer efficiency and pressure drop. A typical design parameter is the difference between the supply and return temperatures to the refrigerator, which usually ranges between 3 and $5 \mathrm{~K}$ in water-to-water devices (EN 1485:2013). In the case of $3 \mathrm{~kW}$ thermal power, this yields from 10 to $17 \mathrm{l} / \mathrm{min}$ flow rate of a $50 \%$ ethylenglycol solution as typically used in automotive applications. The corresponding pressure drop through the mentioned vapour-compression device is 5 to 15 $\mathrm{kPa}$ in each side. Considering that circulation pumps present a typical $60 \%$ efficiency, pumping the fluid through the conventional refrigerator requires between 2.8 and $14.2 \mathrm{~W}$ electric power.

Considering the total electric consumption, the reference vapour-compression device works with a $\mathrm{COP}=2.43$. 


\section{AMRR definition and simulation}

An active magnetic regenerator (AMR) consists of a porous matrix made of magnetocaloric material (MCM). In order to perform the AMR cycle, the regenerator is magnetized and demagnetized in synchronization with an alternating fluid flow that transports heat between the MCM and the ambient or the thermal load. An AMRR includes both the regenerator and the structures employed to generate the magnetic field and the fluid flow.

A permanent-magnet AMRR with rotary architecture and axial fluid flow is studied in this work, since this configuration seems to be the most suitable for practical applications (Kitanovski et al., 2015). In order to approach realistically its behaviour an experimental magnetic field profile has been considered, which corresponds specifically to the machine published in Eriksen et al. (2015). The working fluid is the 50\% ethylenglycol solution employed in the AC loops. The synchronization of the fluid and magnetic profiles has an impact in the AMR performance (Bjørk and Engelbrecht, 2011), but the no-flow times have a detrimental effect (Nielsen et al., 2010). Therefore, the length of the blow period $\left(\tau_{\text {blow }}\right)$ is a variable parameter in this work. For simplicity in the analysis, a nearly step-wise profile has been considered. Figure 2 shows the applied magnetic field $\left(\mu_{0} \mathrm{H}_{\text {app }}\right)$ and fluid flow (m) profiles along the AMR cycle, normalized to an arbitrary maximum value. A negative value of $\dot{m}$ indicates that the fluid flows from the cold end $(x=L)$ to the hot end $(\mathrm{x}=0)$ of the regenerator bed. 


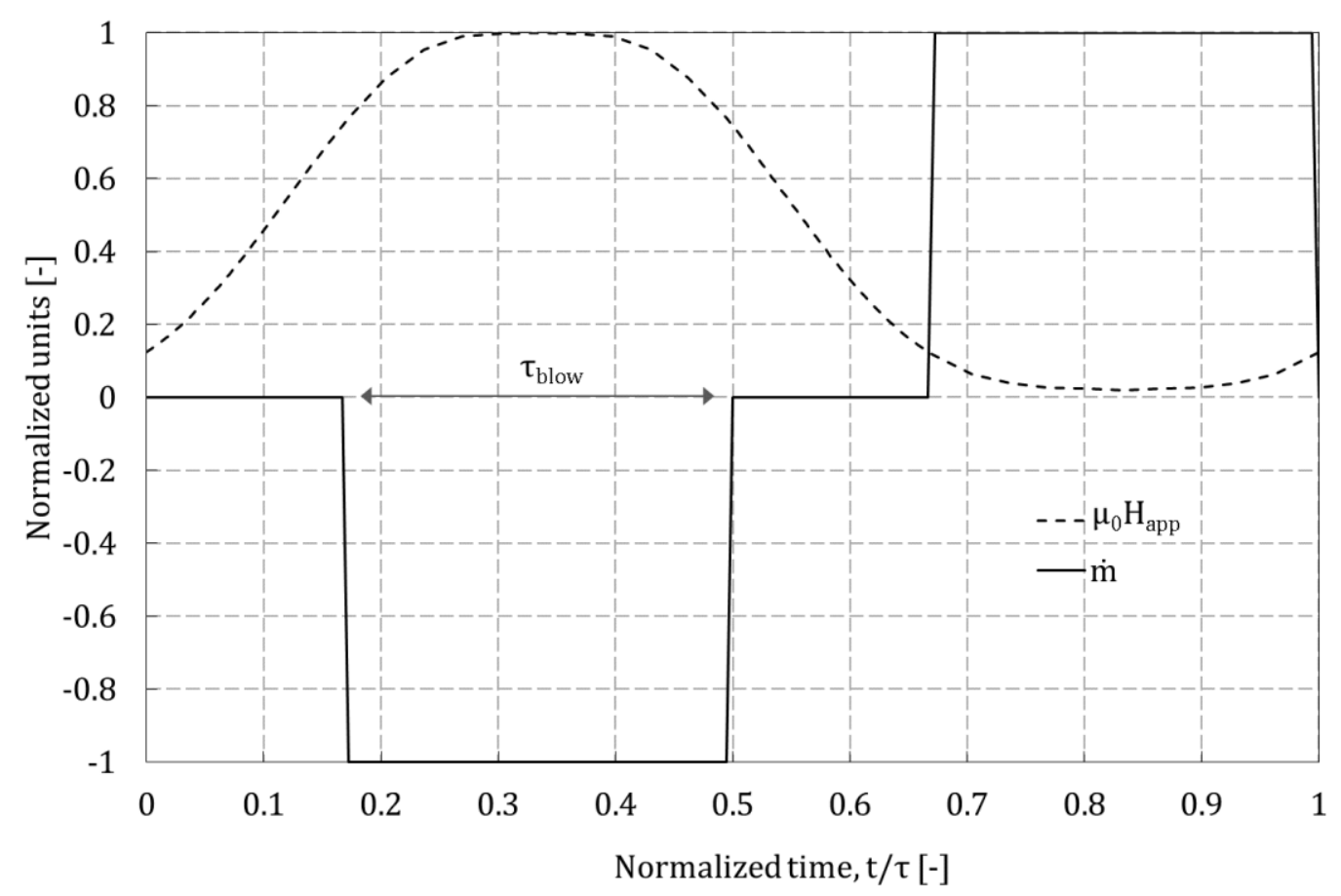

Figure 2. Normalized applied magnetic field and fluid flow profiles.

The AMR is arranged as parallel-plates of MCM. This configuration presents a reduced pressure drop compared to packed spheres and a similar heat transfer performance, provided that the plates are aligned accurately (Kitanovski et al., 2015). In such a case, the fluid flow maldistribution effects can be neglected. Regarding the AMR composition, a multimaterial bed with suitable Curie temperatures is needed to reach the large thermal requirements of the vehicle with a reasonable amount of MCM. Given the availability of detailed experimental data set of commercial-grade Gd properties, the behaviour of the $\mathrm{Gd}$ alloys has been approximated by shifting the former properties as described in Monfared and Palm (2015). The specific AMR composition considered is presented in the results section.

\section{Calculation of the AMRR performance}

In order to fulfill the thermal demand of the vehicle cabin, the AMRR requires electric power to move the magnet assembly and to pump the working fluid through its hydraulic system. The power consumption $\left(\dot{\mathrm{W}}_{\text {elec}}\right)$ depends on the efficiency of the electric energy conversion into mechanical work $(\eta)$, on the pumping power $\left(\dot{\mathrm{W}}_{\text {pump }}\right)$ and on the magnetic power $\left(\dot{\mathrm{W}}_{\text {mag }}\right)$ (Equation 1). 


$$
\dot{\mathrm{W}}_{\mathrm{elec}}=\frac{\dot{W}_{\text {pump }}}{\eta_{\text {pump }}}+\frac{\dot{W}_{\text {mag }}}{\eta_{\text {motor }}}
$$

magnetic power is related to the AMR performance by means of the energy balance equation (Equation 2), while the pumping power through the parallel-plate regenerator is given by Equation 3. The thermal losses to the ambient and the pressure drop through the valves of the device have not been considered.

$$
\begin{gathered}
\dot{\mathrm{W}}_{\text {mag }}=\dot{\mathrm{Q}}_{\mathrm{h}}-\dot{\mathrm{Q}}_{\mathrm{c}}-\dot{\mathrm{W}}_{\text {pump }} \\
\dot{\mathrm{W}}_{\text {pump }}=\frac{\dot{\mathrm{m}}}{\rho_{\mathrm{f}}} \Delta \mathrm{p}
\end{gathered}
$$

The coefficient of performance (COP) of the device is defined based on the total power consumption (Equation 4).

$$
\mathrm{COP}=\frac{\dot{\mathrm{Q}}_{\mathrm{c}}}{\dot{\mathrm{W}}_{\text {elec }}}
$$

The AMR performance has been calculated by means of a computationally efficient numerical 1D model. The model receives as inputs the applied magnetic field and fluid flow profiles and solves the coupled energy balance equations in the fluid and the solid parts of the AMR (Equation 5 and 6).

$$
\begin{aligned}
& \varepsilon A_{c} \rho_{f} c_{f} \frac{\partial T_{f}}{\partial t}=-v \varepsilon A_{c} \rho_{f} c_{f} \frac{\partial T_{f}}{\partial x}+\varepsilon A_{c} k_{f} \frac{\partial^{2} T_{f}}{\partial x^{2}}+h a_{s} A_{c}\left(T_{r}-T_{f}\right)+\frac{\partial p}{\partial x} \frac{\dot{m}}{\rho_{f}} \\
& (1-\varepsilon) A_{c} \rho_{r} \frac{\partial c_{r} T_{r}}{\partial t}=(1-\varepsilon) A_{c} k_{r} \frac{\partial^{2} T_{r}}{\partial x^{2}}+h a_{s} A_{c}\left(T_{f}-T_{r}\right)-(1-\varepsilon) A_{c} \rho_{r} T_{r} \frac{\partial s_{r}}{\partial \mu_{0} H} \frac{\partial \mu_{0} H}{\partial t}
\end{aligned}
$$

The fluid is assumed to enter each side of the regenerator at the corresponding source temperature, $\mathrm{T}_{\mathrm{H}}$ at $\mathrm{x}=0$ and $\mathrm{T}_{\mathrm{C}}$ at $\mathrm{x}=\mathrm{L}$. The equations are solved in a single pair plate-channel which is assumed to be representative of the entire stack. The cooling capacity $\left(\dot{\mathrm{Q}}_{\mathrm{c} \text {,plate }}\right)$ can be obtained from the temperature of the fluid exiting the cold side of the regenerator $\left(\mathrm{T}_{\mathrm{f}}(\mathrm{x}=\mathrm{L})\right)$ (Equation 7). The calculation of the heat rejection $\left(\dot{\mathrm{Q}}_{\mathrm{h}, \text { plate }}\right)$ is analogue.

$\dot{\mathrm{Q}}_{\mathrm{c}, \text { plate }}=\frac{\int_{\mathrm{t}=0}^{\mathrm{t}=\tau}|\mathrm{v}| \varepsilon \mathrm{A}_{\mathrm{c}} \rho_{\mathrm{f}} \mathrm{c}_{\mathrm{f}}\left[\mathrm{T}_{\mathrm{C}}-\mathrm{T}_{\mathrm{f}}(\mathrm{x}=\mathrm{L}, \mathrm{t})\right] \mathrm{dt}}{\tau}$

The governing equations and their numerical implementation were detailed in Torregrosa-Jaime et al. (2015) and the description of the geometrical parameters can be found in Engelbrecht (2008), so only the modelling assumptions that apply to this study are described hereafter. 
The convection heat transfer coefficient between the plates and the fluid $(\mathrm{h})$ is calculated from the generic Nusselt number correlation for laminar flow inside rectangular channels by Muzychka and Yovanovich (2004), which considers the entrance effect. However the possible effect of the frequency has not been considered, due to the lack of suitable correlations to the best knowledge of the authors. Some studies conclude that the heat transfer coefficient may be enhanced in reciprocating flow at high frequency with respect to unidirectional flow (Chen et al., 2014), so the study carried out in this work is conservative in this aspect.

The magnetocaloric properties of the solid part of the regenerator, $\mathrm{c}_{\mathrm{r}}$ and $\partial \mathrm{s}_{\mathrm{r}} / \partial \mu_{0} \mathrm{H}$, are calculated as function of the mean regenerator temperature and the internal magnetic field in each spatial and time step, based on a detailed set of experimental Gd data obtained from Bjørk et al. (2010) which has been shifted in temperature as commented before.

The internal magnetic field $\left(\mu_{0} \mathrm{H}\right)$ is also calculated iteratively in each time and spatial step and is a function of the average demagnetization factor $\left(\mathrm{N}_{\text {avg }}\right)$ and the magnetization of the MCM (M) (Equation 8). The approximation by Nielsen et al. (2012) has been adopted for its implementation.

$$
\mu_{0} H(x, t)=\mu_{0} H_{a p p}(x, t)-N_{\text {avg }}(x, t) \cdot M\left(T(x, t), \mu_{0} H(x, t)\right)
$$

In stacks of parallel plates, $\mathrm{N}_{\mathrm{avg}}$ depends not only on the geometry of the plate but also on the number of plates stacked and the distance between them (Christensen et al., 2011). Therefore, the effect of demagnetization will be affected by the particular arrangement of the MCM in beds, which is a further step of the design process. For the purpose of this analysis, $\mathrm{N}_{\mathrm{avg}}$ has been set to 0.25 for all the studied cases. This is an average $\mathrm{N}_{\text {avg }}$ value of the range obtained by means of the model by Christensen et al. (2011) for the plate dimensions considered in this work.

\section{Calculation of the AMRR mass}

In this study, the mass of the AMRR is the sum of the mass of the magnet assembly and that of MCM. As mentioned above, these magnitudes are directly related to the cost of the machine. The rest of the components (electric motor, valves, etc.) are expected to represent a small percentage of the total mass and cost and are not taken into account. 
The total mass of MCM $\left(\mathrm{m}_{\mathrm{r}}\right)$ needed to meet the thermal demand of the vehicle with a given AMR configuration is inversely proportional to its specific cooling capacity $\left(\dot{\mathrm{q}}_{\mathrm{c}}\right)$, Equation (9).

$$
\mathrm{m}_{\mathrm{r}}=\frac{\dot{\mathrm{Q}}_{\mathrm{c}}}{\dot{\mathrm{q}}_{\mathrm{c}}}=\dot{\mathrm{Q}}_{\mathrm{c}} \frac{\rho_{r} W L H_{r}}{\dot{\mathrm{Q}}_{\mathrm{c}, \text { plate }}}
$$

The mass of the magnet $\left(\mathrm{m}_{\text {mag }}\right)$ required to generate a given magnetic field amplitude $\left(\mu_{0} \mathrm{H}_{\text {app }}\right)$ over the volume occupied by the AMR is estimated with the approach proposed by Bjørk et al. (2011). If an assembly that generates a constant magnetic field in the gap is considered, the volume of the gap is related to the volume of magnet material with remanence $B_{\text {rem }}$ through the figure merit $M^{*}$ (Equation 9).

$$
\mathrm{M}^{*}=\left(\frac{\mu_{0} H_{a p p}}{B_{\text {rem }}}\right)^{2} \frac{\mathrm{V}_{\text {gap }}}{\mathrm{V}_{\text {mag }}}
$$

The value of $M^{*}$ depends on the specific magnet design considered. In order to obtain a plausible estimation of the magnet assembly mass, the expression for the ideal Halbach cylinder of infinite length has been considered as in Bjørk et al. (2011) (Equation 10). The Halbach-like arrays are widely employed in AMRR prototypes (Kitanovski et al. 2015).

$$
\mathrm{M}^{*}=\frac{\left(\frac{\mu_{0} H_{a p p}}{B_{\text {rem }}}\right)^{2}}{e^{2 \frac{\mu_{0} H_{a p p}}{B_{\text {rem }}}}-1}
$$

In most rotary prototypes the AMR is placed inside the magnet gap, therefore the volume of the bore can be assimilated to the volume of the AMR. However in actual finite cylinders, the field drops towards the ends of the magnet. The useful magnet length depends on the dimensions of the bore. In their study, Tura and Rowe (2014) considered a $85 \%$ useful length and their results agree with the detailed analysis by Bjørk et al. (2015). Taking this into account, the magnet mass required can be expressed by arranging Equations 9 and 10, following the deduction by Bjørk et al. (2011) (Equation 12).

$$
\mathrm{m}_{\text {mag }}=\mathrm{m}_{\mathrm{r}} \frac{\rho_{\text {mag }}\left(\mathrm{e}^{\left.2 \mu_{0} \mathrm{H}_{\text {app }} / \mathrm{B}_{\text {rem }}-1\right)}\right.}{0.85 \rho_{\mathrm{r}}(1-\varepsilon)}
$$

\section{Parameter space}

The AMRR performance and hence its resulting mass depend on multiple design and working parameters. With the purpose of determining the most appropriate values for vehicle applications, a 
parametric study has been carried out. Performing a complete study instead of employing an optimization routine will allow for detecting trends that can be useful for future design purposes.

In the simulations, the hot and cold end temperatures were fixed to the values reported in Table 1. Table 2 details the parameters employed in the model that remain constant for all the studied cases. Table 3 shows the parameters which have been varied and their range of values.

\begin{tabular}{|c|c|}
\hline \multicolumn{2}{|c|}{ Table 2. Constant model parameters } \\
\hline Parameter & Value \\
\hline$\rho_{\mathrm{f}}$ & $1030.7 \mathrm{~kg} \mathrm{~m}^{-3}$ \\
\hline $\mathrm{c}_{\mathrm{f}}$ & $3551 \mathrm{~J} \mathrm{~kg}^{-1} \mathrm{~K}^{-1}$ \\
\hline $\mathrm{k}_{\mathrm{f}}$ & $0.394 \mathrm{~W} \mathrm{~m}^{-1} \mathrm{~K}^{-1}$ \\
\hline$\rho_{\mathrm{r}}$ & $7900 \mathrm{~kg} \mathrm{~m}^{-3}$ \\
\hline $\mathrm{k}_{\mathrm{r}}$ & $11 \mathrm{~W} \mathrm{~m}^{-1} \mathrm{~K}^{-1}$ \\
\hline$\rho_{\mathrm{mag}}$ & $7400 \mathrm{~kg} \mathrm{~m}^{-3}$ \\
\hline $\mathrm{B}_{\mathrm{rem}}$ & $1.4 \mathrm{~T}$ \\
\hline $\mathrm{N}_{\mathrm{avg}}$ & 0.25 \\
\hline $\mathrm{W}$ & $25 \mathrm{~mm}$ \\
\hline$\eta_{\text {pump }}$ & 0.60 \\
\hline$\eta_{\text {motor }}$ & 0.85 \\
\hline
\end{tabular}

\begin{tabular}{|c|c|c|c|}
\hline \multicolumn{4}{|c|}{ Table 3. Variable model parameters } \\
\hline Parameter & Range & Values for first run & Values for second run \\
\hline $\mathrm{H}_{\mathrm{f}}$ & $0.1-0.01 \mathrm{~mm}$ & $0.1,0.05,0.01 \mathrm{~mm}$ & $0.05,0.04,0.03,0.02 \mathrm{~mm}$ \\
\hline$\varepsilon$ & $0.25-0.48$ & $0.25,0.33,0.40$ & $0.33,0.36,0.40,0.44,0.48$ \\
\hline $\mathrm{L}$ & $50-12.5 \mathrm{~mm}$ & $50,25,12.5 \mathrm{~mm}$ & $30,25,20,15,10,7.5 \mathrm{~mm}$ \\
\hline$\mu_{0} \mathrm{H}_{\text {app }}$ & $1-1.4 \mathrm{~T}$ & $1,1.2,1.4 \mathrm{~T}$ & $1.4 \mathrm{~T}$ \\
\hline$\tau_{\text {blow }} / \tau$ & $0.25,0.33,0.4$ & 0.33 & 0.33 \\
\hline $\mathrm{f}$ & $1-10 \mathrm{~Hz}$ & $1,2,4,6,8 \mathrm{~Hz}$ & $2,3,4,5,6,8,10 \mathrm{~Hz}$ \\
\hline $\mathrm{U}$ & $0.2-1$ & $0.2,0.4,0.6,0.8,1$ & $0.2,0.3,0.4,0.5,0.6$ \\
\hline
\end{tabular}

The design parameters varied in the study include the regenerator dimensions (except for the regenerator width W), the amplitude of the applied magnetic field $\left(\mu_{0} \mathrm{H}_{\text {app }}\right)$ and the duration of the blow time ( $\left.\tau_{\text {blow }}\right)$ with respect to the total cycle time $(\tau)$. The range of channel heights $\left(\mathrm{H}_{\mathrm{f}}\right)$ and porosities $(\varepsilon)$ starts at the state-ofart dimensions of experimental Gd regenerators (Tušek et al., 2013b). The corresponding plate thicknesses can be deducted as $\varepsilon=\mathrm{H}_{\mathrm{f}} /\left(\mathrm{H}_{\mathrm{r}}+\mathrm{H}_{\mathrm{f}}\right)$. The dimensions of current parallel-plate AMRs (for instance, $\mathrm{H}_{\mathrm{f}}=0.1 \mathrm{~mm}$ and $\mathrm{H}_{\mathrm{r}}=0.3 \mathrm{~mm}$ ) should be further decreased in order to increase the AMR specific cooling capacity (Tušek et al., 2013a) and hence reach the requirements of the vehicle. Therefore, the proposed parameter space considers channel and plate thicknesses up to an order of magnitude less. The regenerator length (L) is varied accordingly starting from a typical value in literature, $50 \mathrm{~mm}$. The applied magnetic field values proposed can be currently reached with permanent magnets and in this work are limited by the magnetocaloric 
properties data set employed. Finally, a sensitivity analysis has been performed in the Results section on the influence in the AMRR performance of the relation $\tau_{\text {blow }} / \tau$.

The working parameters of the AMRR are the cycle frequency (f) and the fluid mass flow rate (m). The latter can be obtained from the thermal utilization (U, Equation 13), which has been defined based on an average $c_{r}$ value of the MCMs considered, $c_{r, a v g}=300 \mathrm{~J} \mathrm{~kg}^{-1} \mathrm{~K}^{-1}$.

$$
\mathrm{U}=\frac{\dot{\mathrm{m}} \mathrm{c}_{\mathrm{f}} \tau_{\text {blow }}}{\mathrm{m}_{\mathrm{r}} \mathrm{c}_{\mathrm{r}, \mathrm{avg}}}
$$

The proposed range of frequencies correspond to the reported posibilities of experimental rotary devices (Eriksen et al., 2015), while the utilization has been varied in the optimal range found by Nielsen et al. (2010).

\section{Results and discussion}

This section presents the calculated AMRR mass and electric consumption which are required to overcome the cooling demand of the addressed vehicle $(3027 \mathrm{~W})$, under the conditions in Table 1 . A parametric study has been carried out by varying the parameters contained in Table 3 . The objective is to determine the combinations of these parameters that define an AMRR that fulfills the requirements in Table 1 with lower combined device mass and electric consumption.

First, the Curie temperatures of the MCMs in the AMR bed is selected. This composition is kept constant for all the subsequent simulations. Afterwards, the proposed parametric study has been carried out in two stages. In the first run, a coarse grid of the varied parameters has been defined (third column of Table 3 ). The aim of this initial parametric study is to find which values should be studied in more detail, as well as to outline performance trends that can help reducing the number of simulations. Based on the results obtained in the first run, a new finer grid of the same parameters is defined (fourth column of Table 3). A second run of simulations is then carried out with this finer grid in order to determine the optimal values of the studied parameters.

\section{Selection of MCMs}

As discussed in the former section, a graded AMR bed made of a series of Gd-like MCMs with suitable Curie temperatures has been considered. A detailed discussion of the optimal AMR bed composition is out 
of the scope of this work, nevertheless the selection of MCMs is key to maximize the device performance. Therefore, a sensitivity analysis with near-optimal approaches has been carried out.

According to Monfared and Palm (2015), the maximum cooling capacity can be obtained by choosing a Curie temperature for each MCM layer equal to its average temperature during the AMR cycle. Assuming a linear temperature distribution along the material yielded near-optimal results. The AMR bed was thus divided in equal length layers made of Gd-like materials whose Curie temperature equals the mean temperature of the range covered by the layer. A sensitivity analysis performed with some of the parameters in Table 3 reveals that, despite the value of the parameters considered, the AMRR cooling capacity and COP increase with the number of layers up to a certain number, which in this case is 3 layers (Figure 3). Adding more layers does not provide a significant improvement. Therefore, for all the simulations performed in the following sections, the AMR bed is composed of 4 MCM layers uniformly distributed.

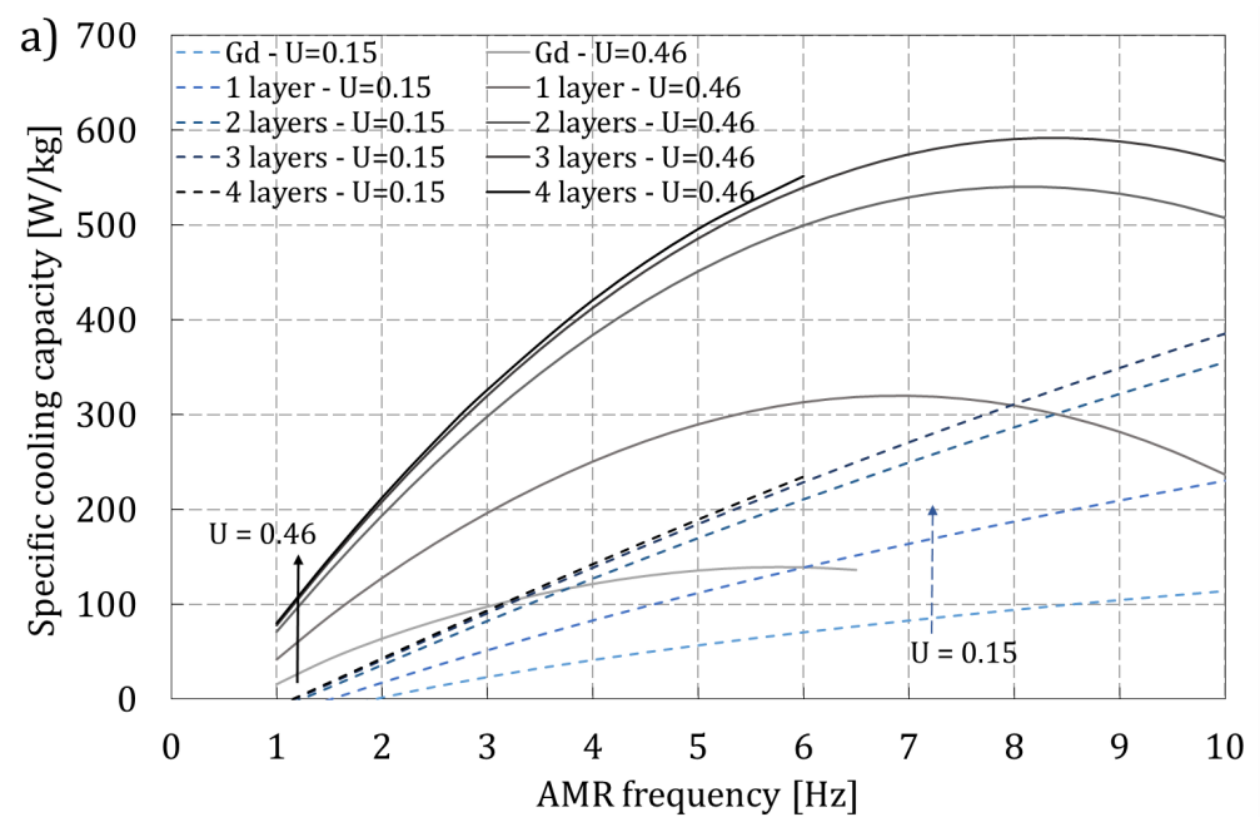




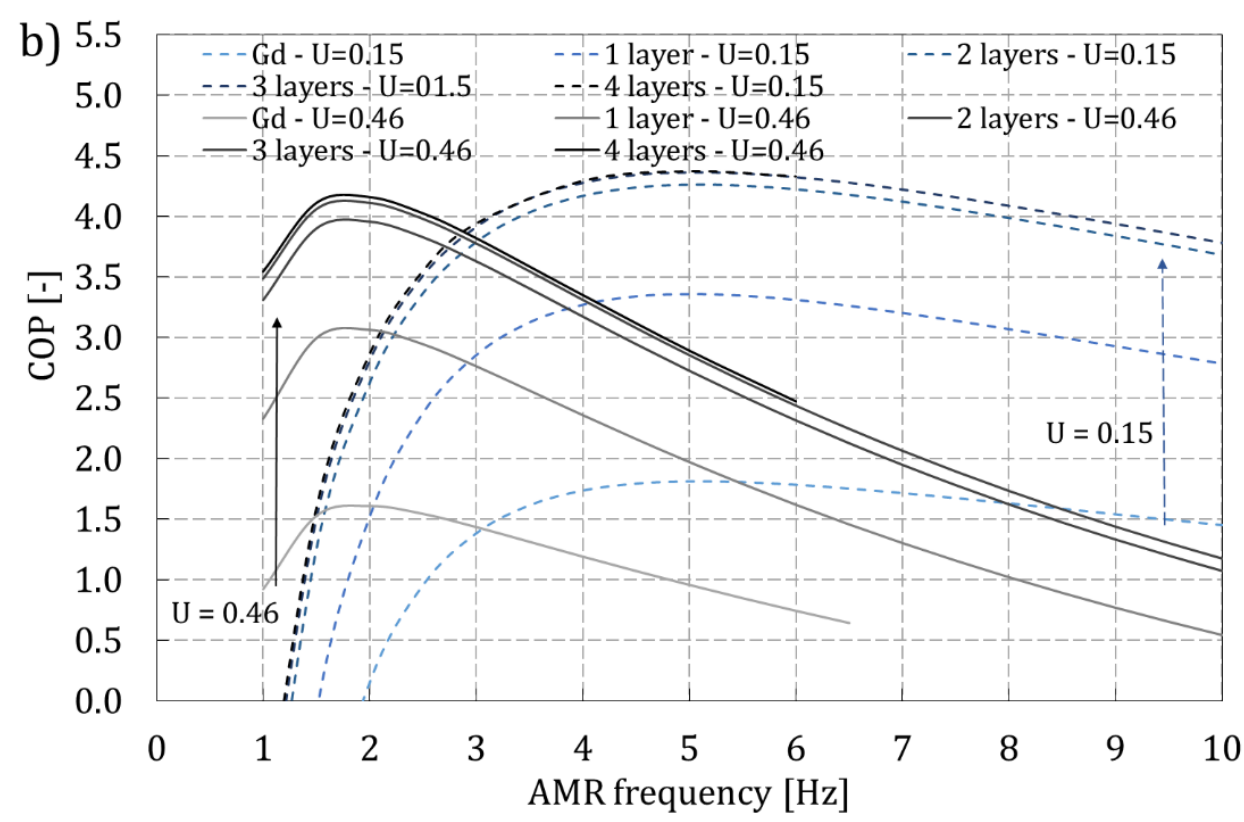

Figure 3. AMRR specific cooling capacity (a) and COP (b) as function of the composition of the bed, the utilization (U) and the frequency. The arrows indicate the evolution of the curves as the number of MCM layers is increased. The results shown were obtained with $\mu_{0} \mathrm{H}_{\mathrm{app}}=1 \mathrm{~T}, \mathrm{H}_{\mathrm{f}}=0.035 \mathrm{~mm}, \varepsilon=0.33, \mathrm{~L}=25 \mathrm{~mm}$, $\tau_{\text {blow }} / \tau=0.33$.

\section{Cooling performance}

Initial parametric study

A first sweep was performed over the entire parameter space with the values contained in the third column of Table 3 (2,025 simulations). The simulation of several combinations of the parameters resulted in a negative cooling capacity, mainly those with a too short regenerator length or a too high utilization and frequency. Figure 4 shows the results of the valid cases sorted according to their channel height $\left(\mathrm{H}_{\mathrm{f}}\right)$ and length (L). 


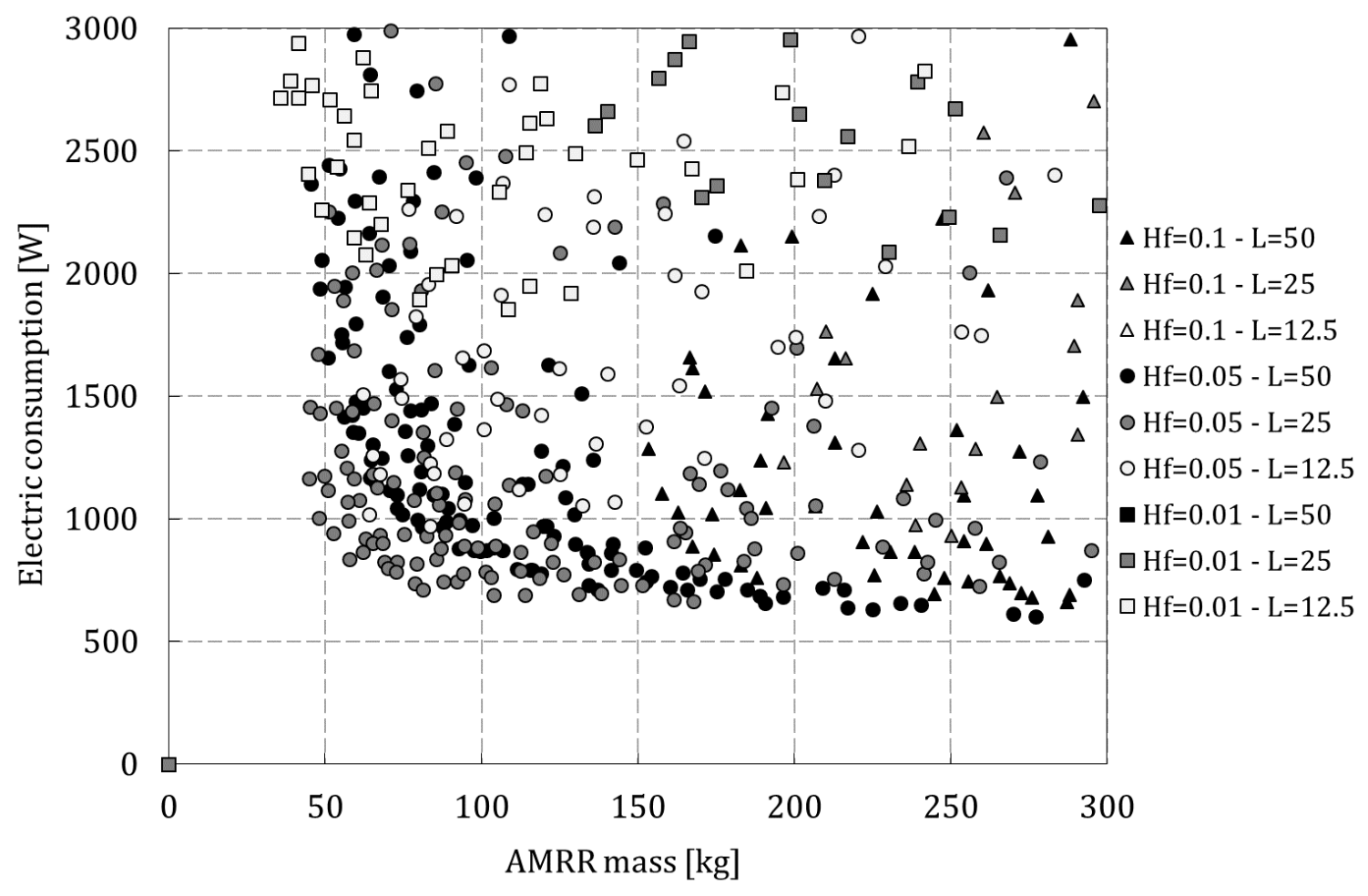

Figure 4. AMRR consumption and mass as function of $\mathrm{H}_{\mathrm{f}}$ and $\mathrm{L}$ expressed in $\mathrm{mm}$.

The simulation results in Figure 4 show that there is an optimal channel height around $0.05 \mathrm{~mm}$ (circles) that provides a compromise between heat transfer efficiency and pressure losses, that is, between specific cooling capacity and pumping work. The specific cooling capacity is related to the AMRR mass through Equations 9 and 12, while the pumping power is a part of the electric consumption (Equation 1). Larger channel heights (triangles) present reduced pressure losses but low specific cooling capacity, so they are placed in the bottom right-hand side of the map. Narrower channel heights (squares) are found in the opposite side. As the channel height decreases, the optimal regenerator length becomes shorter due to the increased pressure losses.

Figure 5 shows the trends produced by the applied magnetic field $\left(\mu_{0} \mathrm{H}_{\mathrm{app}}\right)$, the utilization (U) and the frequency (f). In all the cases studied, the lowest combined mass and power consumption was found with the maximum value of the applied magnetic field considered, 1.4 T (squares in Figure 5). This value was also observed by Tura and Rowe (2014) and Bjørk et al. (2015). The optimum values of the utilization are in between 0.2 and 0.6 , while the optimum frequency depends on the utilization. 


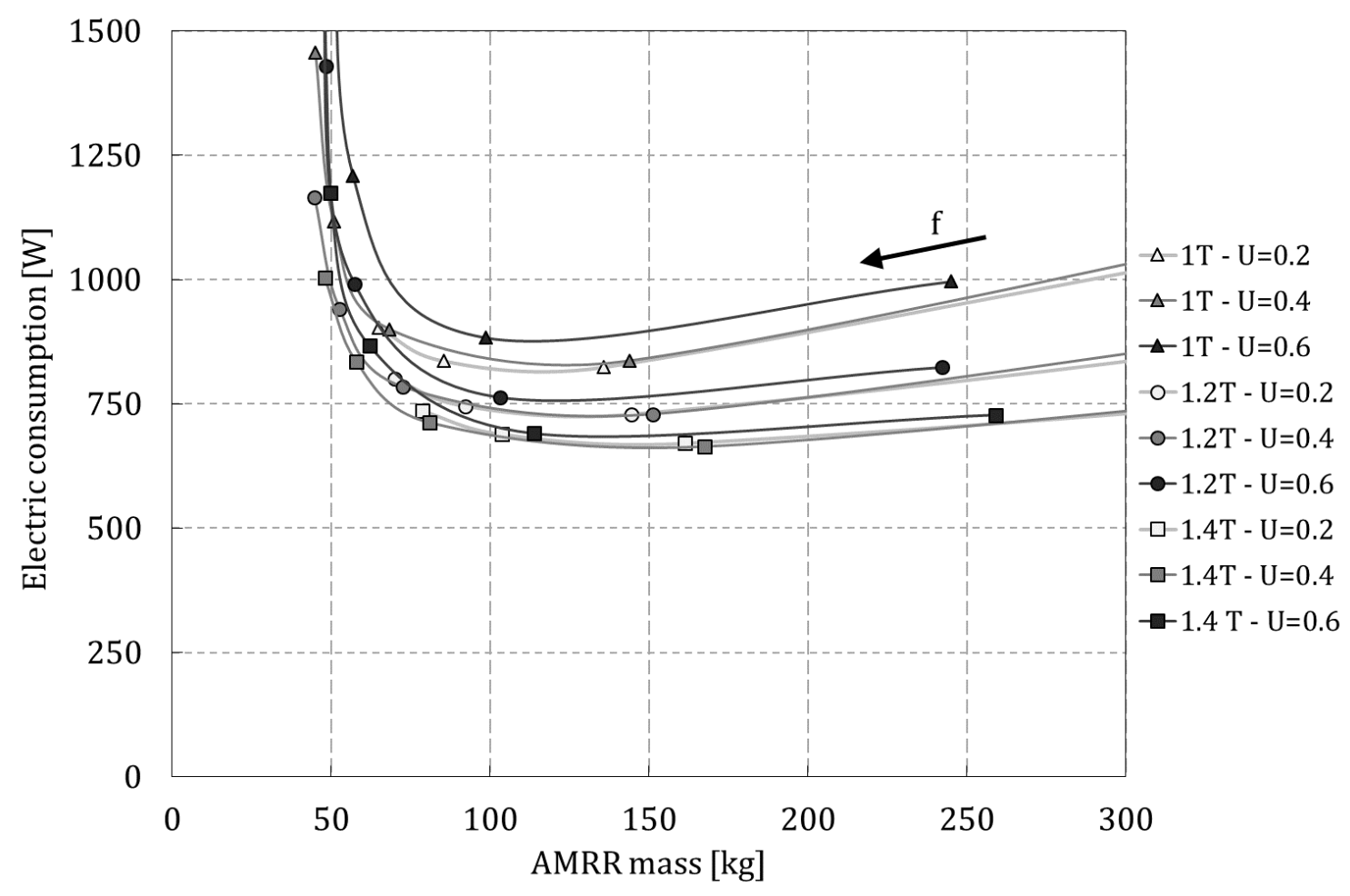

Figure 5. AMRR consumption and mass as function of $\mu_{0} \mathrm{H}_{\text {app }}, \mathrm{U}$ and $\mathrm{f}$, for the case $\mathrm{H}_{\mathrm{f}}=0.05 \mathrm{~mm}, \varepsilon=0.40$, $\mathrm{L}=25 \mathrm{~mm}$. The lines are guides to eye and indicate the trend due to the variation of the frequency (f).

Regarding the effect of the porosity $(\varepsilon)$, the best results were obtained with $\varepsilon=0.40$, the highest value simulated in this first run. Therefore, in order to draw conclusions about its effect in the AMRR performance, the range simulated has been enlarged and refined as described in the following section.

Finally, a sensitivity analysis has been carried out on the value of the blow time with respect to the cycle time $\left(\tau_{\text {blow }} / \tau\right)$. Simulations were performed with a channel height $\mathrm{H}_{\mathrm{f}}=0.05 \mathrm{~mm}$ and the three values of $\tau_{\text {blow }} /$ $\tau$ contained in the second column of Table 3 . The rest of the parameters took the values detailed in the third column of that table (1,350 additional simulations). In order to achieve the desired value of $\mathrm{U}$ regardless of the value of $\tau_{\text {blow }} / \tau$, the amplitude of the flow rate is calculated accordingly in the simulations (Equation 11 ). The results in Figure 6 show that, for the magnetic field profile considered, both $\tau_{\text {blow }} / \tau=0.33$ and 0.40 
(circles and triangles) produce similar results, while shorter blow times such as $\tau_{\text {blow }} / \tau=0.25$ (squares) degrade significantly the AMRR performance.

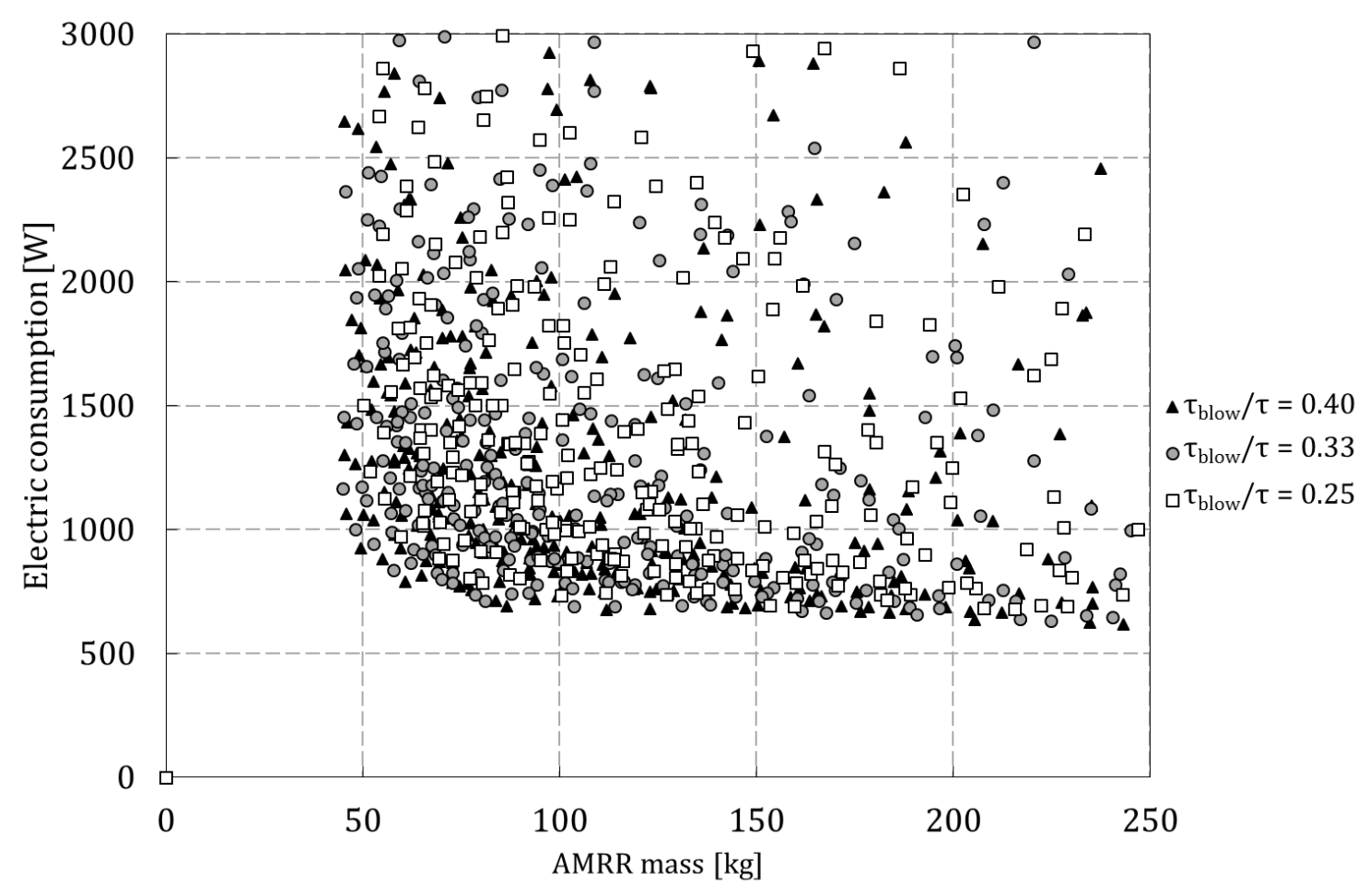

Figure 6. AMRR consumption and mass for the cases with $\mathrm{H}_{\mathrm{f}}=0.05 \mathrm{~mm}$ as function of the blow time.

\section{Detailed parametric study}

The results obtained in the initial parametric study allowed for defining a second parameter sweep around the optimal design values found, which are detailed in the fourth column of Table $3(2,077$ simulations). Figure 7 shows the relevant results of this second run, framed in the mass and electric consumption values of application in MAC systems, compared to the current technology. 

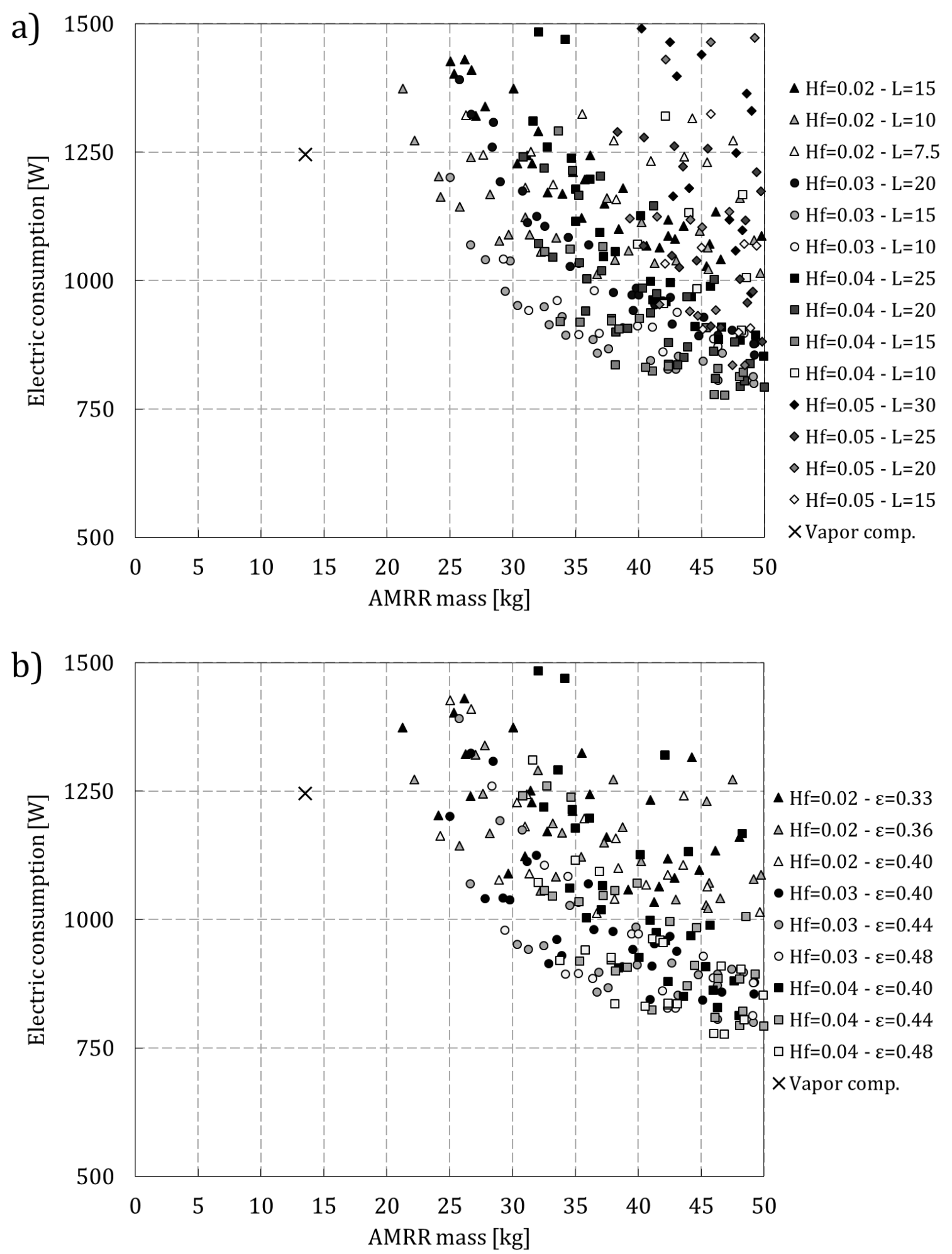

Figure 7. AMRR consumption and mass of application in vehicles considering the features of vapor compression systems (cross), as function of (a) $\mathrm{H}_{\mathrm{f}}(\mathrm{mm})$ and $\mathrm{L}(\mathrm{mm})$ and $(\mathrm{b}) \mathrm{H}_{\mathrm{f}}(\mathrm{mm})$ and $\varepsilon$. 
The trends derived from the results in Figure 4 are confirmed by this detailed parametric study (Figure 7). For the conditions set in this work, the optimal channel height is found between 0.04 and $0.02 \mathrm{~mm}$, depending on mass or efficiency priority. The order of magnitude matches the one predicted by Tušek et al. (2013a) for less demanding conditions, 0.035 to $0.075 \mathrm{~mm}$. A new result is that the regenerator length has a significant influence in the studied conditions. Thinner channels require shorter regenerator lenghts in order to cope with the increase of the pressure drop (Figure 7a).

The optimal porosity is reduced as the channel height decreases (Figure 7b). For a channel height of 0.02 $\mathrm{mm}$ the optimal porosity range was found between 0.33 and 0.40 , while channel heights of $0.03 \mathrm{~mm}$ work better with a porosity between 0.40 and 0.48 . Therefore, there is an optimum plate thickness between 0.03 and $0.04 \mathrm{~mm}$ for all cases. These results agree with the AMR application range predicted by Kitanovski et al. (2015).

All the cases that minimize both electric consumption and mass were obtained with an AMR frequency of $10 \mathrm{~Hz}$, the maximum considered. The corresponding utilization values depend on the channel height. The optimal utilization increases as the channel height decreases and it is found between 0.4 and 0.6. Considering the dimensions of the channels, these values of the working parameters result in optimal flow rates from 51.5 to $65.4 \mathrm{l} / \mathrm{min}$ and pressure drops of 0.46 to $2.27 \mathrm{bar}$. In the upper limit of the pressure drop range, which is produced with the $0.02 \mathrm{~mm}$ high channels, the energy consumption by the pump and the electric motor are practically the same. Compared to the typical values of flow rates in vapour-compression based MAC systems, the ones obtained for AMRRs are significantly higher in agreement with previous findings (Engelbrecht, 2008).

To summarize the findings of this study, Table 4 contains the values of the parameters that define the points in the optimal front outlined in Figure 7. These are the points that satisfy the vehicle requirements (3027 W cooling capacity at $29.4 \mathrm{~K}$ temperature span, Table 1) with minimum combined mass and electric consumption.

\begin{tabular}{|c|c|c|c|c|c|c|c|c|c|c|}
\hline \multicolumn{10}{|c|}{ Table 4. Optimal parallel-plates AMRR features for studied vehicle application } \\
\hline $\begin{array}{c}\text { Mass } \\
(\mathbf{k g})\end{array}$ & $\begin{array}{c}\mathbf{W}_{\text {elec }} \\
(\mathbf{W})\end{array}$ & $\begin{array}{c}\mathbf{C O P} \\
(-)\end{array}$ & $\begin{array}{c}\mathbf{H}_{\mathbf{f}} \\
(\mathbf{m m})\end{array}$ & $\begin{array}{c}\mathbf{\varepsilon} \\
(-)\end{array}$ & $\begin{array}{c}\mathbf{L} \\
(\mathbf{m m})\end{array}$ & $\begin{array}{c}\boldsymbol{\mu}_{\mathbf{0}} \mathbf{H}_{\text {app }} \\
(\mathbf{T})\end{array}$ & $\begin{array}{c}\boldsymbol{\tau}_{\text {blow }} / \boldsymbol{\tau} \\
(-)\end{array}$ & $\begin{array}{c}\mathbf{f} \\
(\mathbf{H z})\end{array}$ & $\begin{array}{c}\mathbf{U} \\
(-)\end{array}$ & $\begin{array}{c}\dot{\mathbf{m}} \\
(\mathbf{1} / \mathbf{m i n})\end{array}$ \\
\hline 21.24 & 1373.8 & 2.20 & 0.02 & 0.33 & 10 & 1.4 & 0.33 & 10 & 0.6 & 55.02 \\
\hline 22.18 & 1272.4 & 2.38 & 0.02 & 0.36 & 10 & 1.4 & 0.33 & 10 & 0.6 & 55.34 \\
\hline 24.10 & 1203.0 & 2.52 & 0.02 & 0.33 & 10 & 1.4 & 0.33 & 10 & 0.5 & 52.02 \\
\hline 24.25 & 1162.8 & 2.60 & 0.02 & 0.40 & 10 & 1.4 & 0.33 & 10 & 0.6 & 57.02 \\
\hline 25.77 & 1144.2 & 2.65 & 0.02 & 0.36 & 10 & 1.4 & 0.33 & 10 & 0.5 & 53.57 \\
\hline
\end{tabular}




\begin{tabular}{|l|c|c|c|c|c|c|c|c|c|c|}
\hline 26.64 & 1069.9 & 2.83 & 0.03 & 0.44 & 15 & 1.4 & 0.33 & 10 & 0.6 & 58.77 \\
\hline 27.80 & 1041.6 & 2.91 & 0.03 & 0.40 & 15 & 1.4 & 0.33 & 10 & 0.5 & 54.48 \\
\hline 29.36 & 979.8 & 3.09 & 0.03 & 0.48 & 15 & 1.4 & 0.33 & 10 & 0.6 & 60.46 \\
\hline 30.33 & 952.1 & 3.18 & 0.03 & 0.44 & 15 & 1.4 & 0.33 & 10 & 0.5 & 55.76 \\
\hline 31.21 & 943.2 & 3.21 & 0.03 & 0.44 & 10 & 1.4 & 0.33 & 10 & 0.6 & 68.86 \\
\hline 32.84 & 915.3 & 3.31 & 0.03 & 0.40 & 15 & 1.4 & 0.33 & 10 & 0.4 & 51.48 \\
\hline 34.21 & 894.8 & 3.38 & 0.03 & 0.48 & 15 & 1.4 & 0.33 & 10 & 0.5 & 58.71 \\
\hline 36.34 & 886.7 & 3.41 & 0.03 & 0.48 & 15 & 1.4 & 0.33 & 10 & 0.6 & 59.87 \\
\hline 36.69 & 859.8 & 3.52 & 0.03 & 0.44 & 15 & 1.4 & 0.33 & 10 & 0.4 & 53.96 \\
\hline 38.13 & 836.9 & 3.62 & 0.04 & 0.48 & 15 & 1.4 & 0.33 & 10 & 0.5 & 65.45 \\
\hline 40.53 & 831.6 & 3.64 & 0.04 & 0.48 & 15 & 1.4 & 0.33 & 10 & 0.6 & 66.77 \\
\hline 41.08 & 824.2 & 3.67 & 0.04 & 0.44 & 15 & 1.4 & 0.33 & 10 & 0.4 & 60.43 \\
\hline 45.98 & 778.4 & 3.89 & 0.04 & 0.48 & 15 & 1.4 & 0.33 & 10 & 0.4 & 63.13 \\
\hline 46.81 & 778.0 & 3.89 & 0.04 & 0.48 & 15 & 1.4 & 0.33 & 10 & 0.5 & 64.27 \\
\hline
\end{tabular}

\section{Conclusion}

A comprehensive parametric study consisting of 5,452 simulations has been conducted with the purpose of determining the optimal design and working parameters of an AMRR for automotive applications. The results show that, considering the possibilities of current permanent-magnet AMRR prototypes and Gd-like MCMs, the cooling requirements of a vehicle could be fulfilled by an AMRR of 20 to $50 \mathrm{~kg}$ working with a COP between 2 and 4. If a parallel-plate AMR is considered, channel heights between 0.02 and $0.05 \mathrm{~mm}$ and plate thicknesses between 0.03 and $0.04 \mathrm{~mm}$ should be employed to achieve such performance. Its lenght should range between 10 and $25 \mathrm{~mm}$ in order to achieve an optimal compromise between heat transfer and pressure losses. From these results, it can be concluded that future developments of AMRs should focus in the manufacturability of MCMs, as also observed in Kitanovski et al. (2015).

The optimal operating parameters were found around 0.4 and 0.6 utilization and $10 \mathrm{~Hz}$ AMR cycle frequency. This values can be reached with current prototypes, but the resulting total fluid flow rates are at least 3 times larger than those usually employed in the hydraulic loops of conventional vapor-compression systems. In order to integrate the AMRR in a MAC system and avoid a secondary loop, the coolant-to-air heat exchangers should be redesigned.

\section{Acknowledgements}

The authors acknowledge C. R. H. Bahl, K. Engelbrecht and K. Nielsen from DTU Energy for the joint work in the AMR model. The supply of the experimental Gd properties and the code of the demagnetization 
model is greatly appreciated. The author acknowledges the Spanish Ministry of Education, Culture and Sport (Ministerio de Educación, Cultura y Deporte) for receiving the Research Fellowship FPU ref. AP2010-2160.

\section{Nomenclature}

\begin{tabular}{|c|c|c|c|}
\hline $\mathrm{A}_{\mathrm{c}}$ & Cross-sectional area $\left[\mathrm{m}^{2}\right]$ & Greek & \\
\hline$a_{s}$ & Specific surface area $\left[\mathrm{m}^{2} \mathrm{~m}^{-3}\right]$ & $\varepsilon$ & Porosity [-] \\
\hline $\mathrm{B}_{\mathrm{rem}}$ & Permanent magnet remanence $[\mathrm{T}]$ & $\mu_{0} \mathrm{H}$ & Magnetic field $[\mathrm{T}]$ \\
\hline $\mathrm{c}$ & Specific heat capacity $\left[\mathrm{J} \mathrm{K}^{-1} \mathrm{~kg}^{-1}\right]$ & $\rho$ & Density $\left[\mathrm{kg} \mathrm{m}^{-3}\right]$ \\
\hline \multirow[t]{2}{*}{$\mathrm{COP}$} & Coefficient of performance [-] & $\tau$ & Period $[\mathrm{s}]$ \\
\hline & & $\tau_{\text {blow }}$ & Fluid blow time $[\mathrm{s}]$ \\
\hline $\mathrm{f}$ & Frequency $[\mathrm{Hz}]$ & $\eta$ & Efficiency [-] \\
\hline $\mathrm{H}$ & Height $[\mathrm{m}]$ & & \\
\hline $\mathrm{h}$ & Convection coefficient $\left[\mathrm{W} \mathrm{K}^{-1} \mathrm{~m}^{-2}\right]$ & Subscripts & \\
\hline $\mathrm{k}$ & Thermal conductivity $\left[\mathrm{W} \mathrm{K}^{-1} \mathrm{~m}^{-1}\right.$ ] & app & Applied \\
\hline $\mathrm{L}$ & Length $[\mathrm{m}]$ & $\mathrm{C}$ & Cold \\
\hline M & Magnetization [M] & $\mathrm{c}$ & Cooling \\
\hline $\mathrm{m}$ & Mass $[\mathrm{kg}]$ & elec & Electric \\
\hline$\dot{\mathrm{m}}$ & Mass flow rate $\left[\mathrm{kg} \mathrm{s}^{-1}\right]$ & $\mathrm{f}$ & Fluid \\
\hline $\mathrm{N}_{\mathrm{avg}}$ & Average demagnetization factor [-] & $\mathrm{H}$ & Hot \\
\hline $\mathrm{p}$ & Pressure $[\mathrm{Pa}]$ & $\mathrm{h}$ & Heating \\
\hline$\dot{\mathrm{Q}}$ & Thermal power [W] & & \\
\hline$\dot{\mathrm{q}}$ & Specific capacity $\left[\mathrm{W} \mathrm{kg}^{-1}\right]$ & mag & Magnet \\
\hline s & Specific entropy $\left[\mathrm{J} \mathrm{K}^{-1}\right]$ & motor & Electric motor \\
\hline $\mathrm{T}$ & Temperature $[\mathrm{K}]$ & & \\
\hline $\mathrm{t}$ & Time $[\mathrm{s}]$ & plate & Per pair plate-channel \\
\hline $\mathrm{U}$ & Thermal utilization [-] & pump & Pump \\
\hline $\mathrm{V}$ & Volume $\left[\mathrm{m}^{3}\right]$ & $\mathrm{r}$ & Solid regenerator material \\
\hline $\mathrm{v}$ & Velocity $\left[\mathrm{m} \mathrm{s}^{-1}\right]$ & & \\
\hline $\mathrm{W}$ & Width [m] & & \\
\hline$\dot{\mathrm{W}}$ & Power [W] & & \\
\hline $\mathrm{x}$ & Position [m] & & \\
\hline
\end{tabular}

\section{References}

Bjørk, R., C.R.H. Bahl, and M. Katter. 2010. Magnetocaloric properties of LaFe13-x-yCoxSiy and commercial grade Gd. Journal of Magnetism and Magnetic Materials 322: 3882-3888.

Bjørk, R., C.R.H. Bahl, and K.K. Nielsen. 2015. The lifetime cost of a magnetic refrigerator. International 
Journal of Refrigeration.

Bjørk, R., and K. Engelbrecht. 2011. The influence of the magnetic field on the performance of an active magnetic regenerator (AMR). International Journal of Refrigeration 34: 192-203.

Bjørk, R., A. Smith, C.R.H. Bahl, and N. Pryds. 2011. Determining the minimum mass and cost of a magnetic refrigerator. International Journal of Refrigeration 34: 1805-1816.

Bjurling, F., J.M. Corberán, J. Payá, and B. Torregrosa-Jaime. 2014. Control strategies for the airconditioning in electric vehicles. In A. Coronas, and J. C. Bruno [eds.], Avances en ciencias y técnicas del frío VII: libro de actas, 769-777. Tarragona, Spain.

Chen, Z., Y. Utaka, and Y. Tasaki. 2014. Measurement and numerical simulation on the heat transfer characteristics of reciprocating flow in microchannels for the application in magnetic refrigeration. Applied Thermal Engineering 65: 150-157.

Christensen, D. V, K.K. Nielsen, C.R.H. Bahl, and A. Smith. 2011. Demagnetizing effects in stacked rectangular prisms. Journal of Physics D: Applied Physics 44: 215004.

EN 1485:2013. 2013. Air conditioners, liquid chilling packages and heat pumps, with electrically driven compressors, for space heating and cooling. Testing and rating at part load conditions and calculation of seasonal performance. European Standard.

Engelbrecht, K. 2008. A Numerical Model of an Active Magnetic Regenerator Refrigerator with Experimental Validation. PhD Thesis. University of Wisconsin-Madison, Madison, WI.

Eriksen, D., K. Engelbrecht, C.R.H. Bahl, R. Bjørk, K.K. Nielsen, A.R. Insinga, and N. Pryds. 2015. Design and experimental tests of a rotary active magnetic regenerator prototype. International Journal of Refrigeration 58: 14-21.

Farrington, R.B., and J.P. Rugh. 2000. Impact of Vehicle Air-Conditioning on Fuel Economy, Tailpipe Emissions and Electric Vehicle Range. NREL Report.

Jacobs, S., J. Auringer, A. Boeder, J. Chell, L. Komorowski, J. Leonard, S. Russek, and C. Zimm. 2014. The performance of a large-scale rotary magnetic refrigerator. International Journal of Refrigeration 37: 84-91.

Kitanovski, A., J. Tušek, U. Tomc, U. Plaznik, M. Ozbolt, and A. Poredoš. 2015. Magnetocaloric Energy Conversion From Theory to Applications. 1st ed. Springer.

Lee, J.T., S.K. Kwon, Y.S. Lim, M.S. Chon, and D.S. Kim. 2013. Effect of Air-Conditioning on Driving Range of Electric Vehicle for Various Driving Modes. SAE Technical Paper 2013-01-0040.

Leighton, D. 2015. Combined Fluid Loop Thermal Management for Electric Drive Vehicle Range Improvement. SAE International Journal of Passenger Cars - Mechanical Systems 8: 711-720.

Monfared, B., and B. Palm. 2015. Optimization of layered regenerator of a magnetic refrigeration device. International Journal of Refrigeration 57: 103-111.

Muzychka, Y.S., and M.M. Yovanovich. 2004. Laminar Forced Convection Heat Transfer in the Combined Entry Region of Non-Circular Ducts. Journal of Heat Transfer 126: 54-61.

Nielsen, K.K., C.R.H. Bahl, A. Smith, N. Pryds, and J. Hattel. 2010. A comprehensive parameter study of an active magnetic regenerator using a 2D numerical model. International Journal of Refrigeration 33: 753-764.

Nielsen, K.K., A. Smith, C.R.H. Bahl, and U.L. Olsen. 2012. The influence of demagnetizing effects on the performance of active magnetic regenerators. Journal of Applied Physics 112: 94905.

Nielsen, K.K., J. Tusek, K. Engelbrecht, S. Schopfer, A. Kitanovski, C.R.H. Bahl, A. Smith, et al. 2011. Review on numerical modeling of active magnetic regenerators for room temperature applications. International Journal of Refrigeration 34: 603-616.

Torregrosa-Jaime, B., F. Bjurling, J.M. Corberán, F. Di Sciullo, and J. Payá. 2014. Transient thermal model of a vehicle's cabin validated under variable ambient conditions. Applied Thermal Engineering.

Torregrosa-Jaime, B., J.M. Corberán, J. Payá, and J.L. Delamarche. 2015. Thermal characterisation of compact heat exchangers for air conditioning in electric vehicles. In 14th UK Heat Transfer Conference, Edinburgh.

Torregrosa-Jaime, B., J.M. Corberán, J. Payá, and K. Engelbrecht. 2015. An efficient numerical scheme for the simulation of parallel-plate active magnetic regenerators. International Journal of Refrigeration 58: $121-130$.

Torregrosa-Jaime, B., J.M. Corberán, C. Vasile, C. Muller, M. Risser, and J. Payá. 2014. Sizing of a reversible magnetic heat pump for the automotive industry. International Journal of Refrigeration 37: 
$156-164$.

Torregrosa-Jaime, B., J. Payá, and J. Corberan. 2013. Design of efficient air-conditioning systems for electric vehicles. SAE International Journal of Alternative Powertrains 2: 291-303.

Torregrosa-Jaime, B., J. Payá, J. Corberan, C. Malvicino, and F. Di Sciullo. 2013. ICE project: Mobile airconditioning system based on magnetic refrigeration. SAE Technical Papers 2013-01-0238.

Tura, A., and A. Rowe. 2014. Concentric Halbach cylinder magnetic refrigerator cost optimization. International Journal of Refrigeration 37: 106-116.

Tušek, J., A. Kitanovski, and A. Poredoš. 2013. Geometrical optimization of packed-bed and parallel-plate active magnetic regenerators. International Journal of Refrigeration 36: 1456-1464.

Tušek, J., A. Kitanovski, S. Zupan, I. Prebil, and A. Poredoš. 2013. A comprehensive experimental analysis of gadolinium active magnetic regenerators. Applied Thermal Engineering 53: 57-66 